\title{
The Monitoring Interest of BK Virus Load in Renal Allograft Tunisian Recipients: Prospective Study
}

\author{
Yousr Gorgi $^{1}$, Mohamed M. Bacha ${ }^{1,2}$, Imen Sfar ${ }^{1}$, A. Ben Mohamed ${ }^{1}$, Hajer Aounallah-Skhiri ${ }^{3}$, \\ Tarak Dhaouadi ${ }^{1}$, Rafika Bardi ${ }^{1}$, N. Skouri ${ }^{1}$, Ezzeddine Abderrahim ${ }^{2}$, M. Makhlouf ${ }^{1}$, \\ T. Ben Romdhane ${ }^{1}$, S. Jendoubi-Ayed ${ }^{1}$, K. Ayed ${ }^{1}$, Taieb Ben Abdallah ${ }^{1}$ \\ ${ }^{1}$ Immunology Research Laboratory (LR03SP01), University Tunis El Manar, Charles Nicolle Hospital, Tunis, Tunisia \\ ${ }^{2}$ Department of Nephrology and Internal Medecine, Charles Nicolle Hospital, Tunis, Tunisia \\ ${ }^{3}$ National Public Health Institute, Tunis, Tunisia \\ Email: gorgi.yousr@gmail.com
}

Received October 1, 2012; revised November 2, 2012; accepted November 10, 2012

\begin{abstract}
BK virus (BKV) may cause nephropathy in renal transplant recipients receiving immunosuppressive therapy, resulting in renal dysfunction and, possibly graft loss. However, the positive and negative predictive values of BK viral load are still controversial. In this prospective, single-center study, BKV DNA was measured 1, 3 and 6 months after transplantation. The viral load in urine and plasma was quantified with the real-time Q-PCR (Argen kit) in 73 renal allograft recipients Three of them showed acute rejection. To determine the cutoff value of viral load, 60 sera samples of healthy blood donors, matched for age and sex, were tested. The mean plasmatic viral load one month posttransplantation was statistically higher in renal transplant recipients $(17.23 \mathrm{copies} / \mathrm{ml})$ compared to that in controls $(2$ copies $/ \mathrm{ml})(p: 0.06)$. This difference of the distribution of viremia values is more evident in the third and sixth month ( $p$ : 0.002 and 0.010 respectively). Furthermore, analysis of the kinetic of viral load revealed an average rise of viremia at 3 months $(1589.14$ copies $/ \mathrm{ml})$ followed by its decrease at 6 months $(249.75$ copies $/ \mathrm{ml})$. However, the difference was not statistically significant. The same is true for the distribution of values of viruria and in all cases the average viral load was statistically higher in urine than in plasma. In addition, this study did not shown significant relationsheep between viremia/viruria and the occurrence of acute rejection, the renal function deterioration, the source of allograft or immunosuppressive therapy protocol. If the results of this study demonstrate the importance of the replication of BKV in renal transplant patients from the first month compared to that in immunocompetent subjects, the screening of the DNA of this virus does not appear to have a prognostic value in the occurrence of acute rejection. However, the plasma and urine monitoring of BKV load beyond 6 months, not appear to exclude the relationsheep between these two biomarkers and the occurrence of chronic graft dysfunction.
\end{abstract}

Keywords: BK Virus; Renal Transplantation; Urine and Plasma Viral Load; Allograft Dysfunction

\section{Introduction}

BK virus (BKV) is a non-enveloped DNA virus, belonging to the Polyomaviridae family. It is ubiquitous with specific host spectra. Following primary infection, transmitted by the respiratory and probably the oral route, this virus remains latent in uroepithelial cells, in B lymphocytes or in other tissues (spleen, brain). BKV reactivation in urinary tractus, which is usually asymptomatic viruria, may occur in both immunocompetent subjects, and immunocompromised patients leading to polyomavirus associated nephropathy (PVAN) that has recently reported as a cause of allograft failure in renal transplant recipients. This nephropathy seems to be related to the conjunction of an intensive immunosuppressive regiments containing tacrolimus (Tac) or mycophenolate mofetil (MMF), an immuno-allogenic environment, a viral reactivation and a renal tubular damages caused by ischaemia or rejection [1-4]. As previously retrospective studies repported, this PVAN would be associated with loss of allograft function occurring in about half of the cases and with a major fibrosis in more than $75 \%$ of the cases in renal transplantation $[5,6]$. BKV specific antiviral therapy is not yet avaible. Because of this limited therapeutic possibility, the monitoring of the viremia could constitute, an alternative in order to decrease the immunosuppression in some cases [7]. Diagnosis of PVAN is based on the presence of cells with intranuclear viral inclusions, known as "decoy cells" and the histological inconstant viral alterations in specimens from allograft biopsies $[2,8]$ or research of large $\mathrm{T}$ viral antigen by a standard immunohistochemical staining 
using anti-SV40 antibodies. In spite of their good specificity, the sensitivity of these two tests is relatively low. So, some studies recently showed that BKV replication in the allograft has been correlated with the quantification by real-time PCR (Q-PCR) of BKV DNA in urine and/or in plasma samples of renal transplant recipients at risk for $\mathrm{BKV}$ infection and for monitoring response to therapy [9-11].

In this context, a prospective single center study of Tunisian renal transplant recipients, in comparison with healthy controls was conducted in order to quantify BKV DNA in urine and plasma by Q-PCR, to analyse according to the kinetics of samples, the distribution of BKV viremia and the viruria values and to specify the clinical and biological correlations between these two biomarkers and renal transplantation outcome.

\section{Materials and Methods}

\subsection{Patients and Controls}

Between April 2009 and September 2011, 73 patients received kidney transplantation at Tunisian Charles Nicolle hospital were prospectively studied. Their clinical characteristics are shown in Table 1. All patients were followed up (urine samples and peripheral EDTA-blood samples were collected) at regular intervals: 1, 3, and 6 months after transplantation and BKV copies in paired urine and serum samples of them were quantified. Three patients experienced acute rejection episode. In all cases acute rejection occurred between the 7 th and 15th day post-transplantation. Allograft biopsy was performed only in 10 patients ( 3 cases of suspected acute rejection and 7 cases of deteriored renal function with serum creatitine levels increased to more than $25 \%$ of the base line value). The combination immunosuppressive therapy $[\mathrm{Tac}+$ prednisolone $+\mathrm{MMF}]$ was more frequently $(64.38 \%)$, but not statistically significant, prescribed than [Ciclosporine + prednisolone $+\mathrm{MMF}](30.14 \%)$.

To determine the cutoff value of viral load, 60 sera samples of healthy blood donors, matched for age and sex to transplant recipients were tested.

All patients and controls gave informed consent to participate in this study, which was approved by the Ethics Committee of Charles Nicolle Hospital in Tunis.

\subsection{Quantitatve Real-Time PCR (Q-PCR)}

Quantification of viral load in plasma and urine samples of all subjects studied was performed using a commercial kit: BK Virus R-gene ${ }^{\mathrm{TM}}$ (Argene, France) according to the manufacturer's instructions.

\subsection{Statistical Analysis}

Comparison of categoric and continuous data was evaluated by Fisher's Exact Test and Mann-Whitney U-Test (Statview dataset, Institute Inc.).

\section{Results}

\subsection{Distribution of Viremia Values}

As shown in Figure 1, the mean viral load one month post-transplantion was statistically higher in renal transplant recipients [17.23 copies/ml (range: 12.63 to 107.96 copies $/ \mathrm{ml})$ ] compared to that in controls $(2$ copies $/ \mathrm{ml})(p$ : $0.06)$. This difference of the distribution of viremia values is more evident in the third and sixth month ( $p$ : 0.002 and 0.010 respectively).

Furthermore, analysis of the kinetic of viral load revealed an increase in the average value of viremia in 3 months (1589.14 copies $/ \mathrm{ml})$ followed by its decrease at 6 months (249.75 copies/ml).

\subsection{Distribution of Viruria Values}

The kinetic of the BK viruria is similar to that of viremia with a non-significant rise in urinary viral load mean 3 months after transplantation followed by its decrease at sixth month (Figure 2).

Table 1. Epidemiological and clinical characteristics of renal transplant recipients.

\begin{tabular}{lc}
\hline Sex Ratio (M/F) & $55 / 18$ \\
Mean age (years \pm SD) & $37.05 \pm 9.63$ \\
Causes of renal failure: $\mathbf{n}(\%)$ & $34(46.6)$ \\
- Unknown & $14(19.2)$ \\
- Chronic glomerulonephritis (CGN) & $10(13.7)$ \\
- Chronic interstitial nephropathy (CIN) & $15(20.5)$ \\
- Others & $43.67 \pm 36.53$ \\
Mean duration in dialysis (months \pm SD) & $15 / 58$ \\
Source of allografts (CD/LD) & $36.17 \pm 9.6$ \\
Mean donor age (years \pm SD) & \\
Mean sera creatinine: $(\mu \mathrm{mol} / \mathrm{l})$ & $133.97 \pm 31.10$ \\
- 1 st month & $137.33 \pm 17.21$ \\
-3rd month & $129.82 \pm 19.43$ \\
-6th month & \\
Immunosuppression: $\mathbf{n}(\%)$ & $54 / 11 / 8$ \\
-Induction therapy: thymoglobulin/basiliximab/No & $22(30.14)$ \\
-cyclosporin + prednisolone + mycophenolate mofetil & $47(64.38)$ \\
-[tacrolimus + prednisolone + mycophenolate mofetil] & \\
\hline
\end{tabular}

Acute Rejection: n (\%)

$3(4.5)$

CD: cadaveric donor; LD: living related and unrelated donor; $n$ : number; $\mathrm{M}$ : male; F: female. 
Regardless of the date of collection and in all cases the average viral load was statistically higher in urine than in plasma: [1st month: (674122.34 vs. 17.22); 3rd month: (940839.1 vs. 1589.14) and 6th month: (107005.33 vs. 249.75) copies/ml].

\subsection{Viremia and Viruria Values and Clinical or Biological Correlations}

Among 73 studied transplant recipients 30 (41.1\%) had detectable viral load in urine and/or plasma. There is a wide interindividual variation of viremia and viruria. However, four distinct groups of patients were identified (Table 2). G1 includes 12 patients who had only viruria, with a mean of 49063.638 copies/ml (range: $30.38-8.1 \times$ $10^{5}$ copies $/ \mathrm{ml}$ ), G2 is composed of 14 transplant recipients who had both viruria and viremia with mean of 4318913.13 and 65649.69 copies/ml respectively (range: $19.8-4.5 \times 10^{7}$ versus $62.17-10 \times 10^{5}$ ), G3 with 43 patients who did not have detectable $\mathrm{BK}$ viruria and viremia, and G4 includes 4 patients without viruria, although they had viremia, ranging from 44.62 to 807.56 copies/ml (mean: 359.75 copies $/ \mathrm{ml}$ ). Among the 10 renal biopsies performed, 3 showed an aspect suggestive of BKV infection ( 2 in $\mathrm{G} 1$ and 1 in G2).

The average value of viruria were statistically higher in G2 than in G1 [(4318913.13 vs. 49063.64) copies $/ \mathrm{ml}$; $\left.\left(p=10^{-3}\right)\right]$ and that of viremia was also statistically lower in G4 compared to that in G2 [(359.75 vs. 65649.69) copies/ml; $(p=0.016)]$.

In all groups, no significant association was found between viremia/viruria values and the source of the allograft (cadaveric or living donor), immunosuppressive treatment protocol although the combinaison [Tac + prednisolone $+\mathrm{MMF}$ ] was more but not statistically significant prescribed in all groups and serum creatinine levels (Table 2).

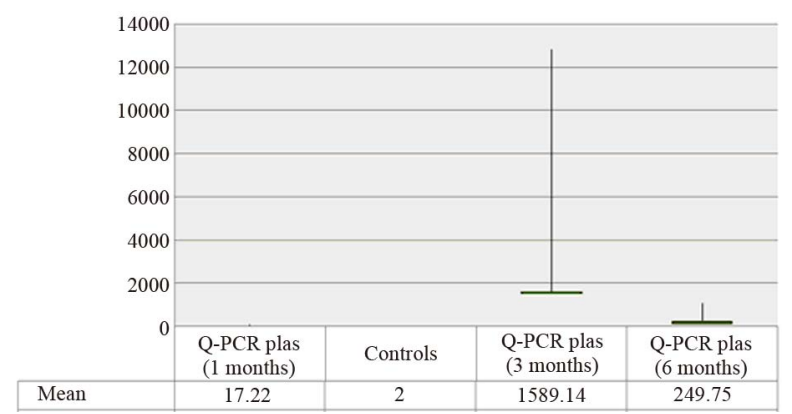

Figure 1. Distribution average values of viremia (copies/ml) in patients and controls.

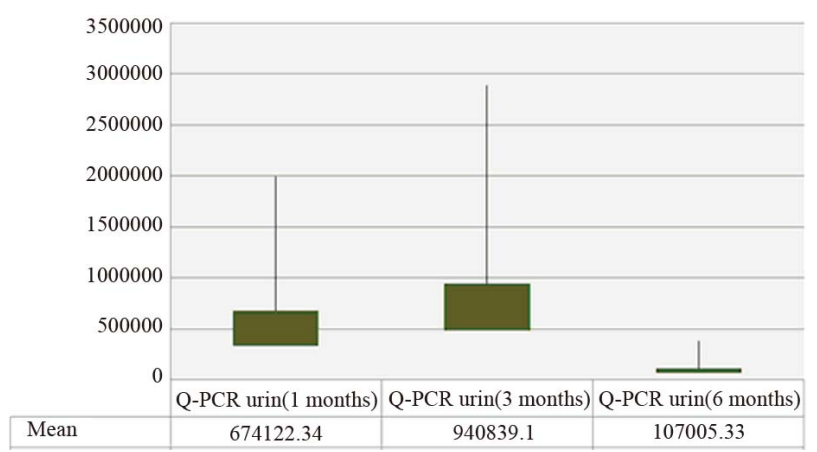

Figure 2. Distribution average values of viruria (copies/ml) in patients.

Table 2. Relationsheeps between viremia/viruria values and clinical/biological characteristics.

\begin{tabular}{|c|c|c|c|c|}
\hline Paramètres & $\begin{array}{c}\operatorname{Vurie}(+), \operatorname{Vmie}(-) \mathrm{G} 1 \\
(\mathrm{n}=12)\end{array}$ & $\begin{array}{l}\text { Vurie }(+), \operatorname{Vmie}(+) \\
\text { G2 }(\mathrm{n}=14)\end{array}$ & $\begin{array}{l}\operatorname{Vurie}(-), \operatorname{Vmie}(-) \\
\text { G3 }(\mathrm{n}=43)\end{array}$ & $\begin{array}{l}\operatorname{Vurie}(-), \operatorname{Vmie}(+) \\
\text { G4 }(\mathrm{n}=4)\end{array}$ \\
\hline Gender Ratio: (M/F) & $11 / 1$ & $9 / 5$ & $32 / 11$ & $3 / 1$ \\
\hline $\begin{array}{l}\text { Mean sera creatinine }{ }^{\mathrm{NS}} \mu \mathrm{mol} / 1 \\
\text { - } 1 \text { st month } \\
\text {-3rd month } \\
\text { - } 6 \text { th month }\end{array}$ & $\begin{array}{l}123.14 \pm 38.23 \\
121.86 \pm 29.07 \\
110.43 \pm 23.61\end{array}$ & $\begin{array}{c}177.33 \pm 113.77 \\
152.44 \pm 52.60 \\
152.22 \pm 58.11\end{array}$ & $\begin{array}{l}131.41 \pm 46.76 \\
123.00 \pm 38.41 \\
117.15 \pm 40.81\end{array}$ & $\begin{array}{c}104.00 \pm 8.48 \\
152.00 \pm 9.89 \\
139.50 \pm 23.33\end{array}$ \\
\hline $\begin{array}{l}\text { Immunosuppression }{ }^{\mathrm{NS}} \\
\text {-Induction: }\end{array}$ & & & & \\
\hline $\begin{array}{l}\text { Thymo + Basil + MMF } \\
\text {-Cic + Pred + MMF (\%) } \\
\text {-Tacr + Pred + MMF }(\%) \\
\text {-Pred + MMF }\end{array}$ & $\begin{array}{c}3 / 9(33.33) \\
4(33.3) \\
6(50) \\
2\end{array}$ & $\begin{array}{c}4 / 10(40) \\
5(35.7) \\
9(64.3) \\
0\end{array}$ & $\begin{array}{c}16 / 27(59.25) \\
14(32.5) \\
27(62.8) \\
2\end{array}$ & $\begin{array}{c}1 / 3(33.33) \\
0 \\
2(50) \\
2\end{array}$ \\
\hline Source of allografts (CD/LD) & $4 / 8$ & $6 / 8$ & $11 / 32$ & $0 / 4$ \\
\hline Acute rejection $^{\mathrm{NS}}$ & - & - & 2 & 1 \\
\hline
\end{tabular}

Thymo: thymoglobulin; Basil: basiliximab; Pred: prednisolone; Cic: ciclosporin; Tac: tacrolimus; MMF: mycophenolate mofetil; NS: not significant. NS : Comparing the averages of creatinine at $1,3,6$-month intervals $(p=0.221 ; p=0.224$ and $p=0.148$ respectively), the percentage of prescription of combination therapy [tacrolimus $+\mathrm{MMF}$ ] and the occurrence of acute rejection reveals no statistically significant differences between groups of patients. 
Similarly, no positive correlation was demonstrated between the occurrence of acute rejection and the number of copies of viral DNA in the urine or in the plasma (Figure 3).

\section{Discussion}

In this study, BK viremia was statistically higher in renal transplant recipients than in controls. This result confirms that the reactivation of BKV in the urinary tract requires a compromised immune system and therefore its high prevalence in allograft recipients immunosuppressed reported by several studies [12-14]. The prevalence of PVAN in renal transplant recipients varies from $10 \%$ to $60 \%$ [15]. In this study, a potential BKVinfection was observed in $41.1 \%$ of cases but the PVAN was only confirmed in $10 \%$ of the aspect suggestive of renal biopsy.

In renal transplant recipients and during immunosuppression, the virus becomes reactivated and in addition to
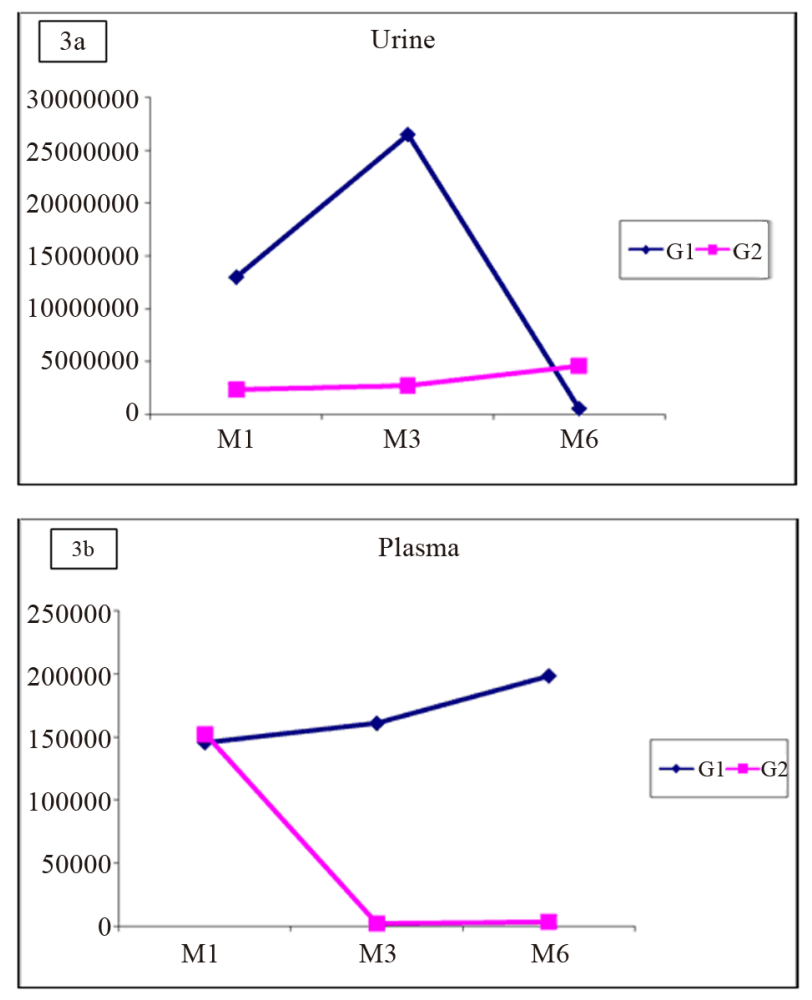

\begin{tabular}{ccccc}
\hline & & 1st Month & 3rd Month & 6th Month \\
\hline Urine & G1 & $12,975,019$ & $26,477,091$ & 532176.91 \\
& G2 & $2,285,483$ & $2,704,945$ & $4,585,313$ \\
Plasma & G1 & 145744.37 & 161,115 & 198714.75 \\
& G2 & 152,506 & 2314 & 3479 \\
\hline
\end{tabular}

Figure 3. Distribution of mean values of viruria and viremia in $\mathbf{G 1}$ and $\mathrm{G} 2$. excretion in the urinary tract, the virus has also been detected in the plasma [16]. So, the monitoring of the viremia could constitute an alternative to identify renal allograft recipients with BKV infection. Several studies on the quantitative relationship between $\mathrm{BK}$ viremia and viruria were conducted suggesting different mechamisms by which $\mathrm{BK}$ viremia can occur $[1,2,16]$. In this cohort, the average viral load in urine predominated in the 1 st and 3rd month post-graft while that in plasma was at the 3rd and 6th month after transplantation would support a viral reactivation in urinary tract involving the passage of trans-urothelial BKV through the peritubular capillary. This mechanism has not been found by Anskar and Merlino et al. reporting that the absence of the quantitative relationship between the two biomarkers may reflect independent BKV reactivation in the urothelium and circulating mononuclear cells during immunosuppression [16-18]. This mechanism of viral reactivation independent in different tissues suggested by these authors could explain the 4 cases of positive viremia without detectable viruria in G4 patients of this study.

Moreover, the fact that, in all cases, the rates of the viruria are statistically higher than those of viremia may also suggest that at least in part, BK viruria would be a manifestation of viremia. These results corroborate those of Cinthia et al. who reported that the viremia is not present in patients with low-level/limited viral replication in the urinary tract.and increasing levels of this biomarker develop only if there is significant tissue damage with progression to PVAN [19].

It is now well established that progression to BKV nephropathy occurs without clinical symptoms, except for increasing serum creatinine concentrations over a period of weeks [20]. This notion could not be confirmed in this study in all groups. Indeed, mean serum creatinine levels at regular post-graft intervals were not statistically higher in one of 4 groups in relation to another.

Immunosuppression, particularly tacrolimus and mycophenolate mofetil, is considered the main risk factor for BKV replication [21,22]. However, it has been shown that the PVAN in renal transplant recipients was more correlated with the degree of immunosuppression than with the use of particular drugs [17,23]. In this study, the distribution values of viruria/viremia was also not related to immunosuppressive therapy although the combinaison $[$ Tac + prednisolone + MMF $]$ was more but not statistically significant prescribed in all groups. Moreover, several studies reported that persistent BKV replication in renal allograft recipients was identified as a cause of progressive graft dysfunction and graft loss linked to immunosuppressive drugs (Tac + MMF) $[3,7,10]$. These findings contrast with those of this study revealed that 3 cases of acute rejections occurred in 2 patients G3 and 1 transplant recipient G4 who received this drug combina- 
tion. In addition, no significant differences were observed when patients, with versus without acute rejection episodes, were compared for the distribution of the Q-PCR values in urine and plasma samples. The small number of patients in G4 compared to in G1, G2 or G3 may reflect this consequent loss of statistical power for the various relationships sought between the quantification of viral load and clinical or biological characteristics of studied patients.

Following this study, the results corroborate those of Hirsch, presented at the XIth annual congress of the "Société Francophone de Transplantation" (Montpellier, France, 7-10 Dec. 2011), reporting that BKV infection, viral activation/replication and PVAN would be different entities in which the screening of the DNA of BK virus does not appear to have a pronostic value on the occurrence of acute rejection but it is key to early intervention for possible degradation of renal function related to this $\mathrm{BKV}$ infection. Indeed, the evolution to the PVAN in renal transplant recipients with positive viremia is influenced by the conduct towards the immunosuppression. In absence of efficiency demonstrated by the anti-viral treatment, the corticoids and the polyvalent immunoglobulins, the reduction in the immunosuppression can be responsible for a stabilization of the renal function.

\section{Conclusion}

The plasma and urine monitoring of BKV load in renal allograft Tunisian recipients, in the medium to long term, using Q-PCR as a non-invasive diagnostic tool of PVAN before any signs of renal function deterioration, can objectify a relationship between these two biomarkers and the occurrence of chronic graft dysfunction.

\section{Acknowledgements}

This study was supported by a grant for Tunisian kidney transplantation and renal pathology research fund [(LR03SP01) (LR00SP01)] and MEDIS Laboratory.

\section{REFERENCES}

[1] C. Bressollette-Bodin, M. Coste-Burel, M. Hourmant, V. Sebille, E. Andre-Garnie and B. M. Imbert-Marcille, "A Prospective Longitudinal Study of BK Virus Infection in 104 Renal Transplant Recipients," American Journal of Transplantation, Vol. 5, No. 8, 2005, pp. 1926-1933. doi:10.1111/j.1600-6143.2005.00934.x

[2] V. Nickeleit, H. H. Hirsch, M. Zeiler, F. Gudat, O. Prince, G. Thiel and M. J. Mihatsch, "BK-Virus Nephropathy in Renal Transplants-Tubular Necrosis, MHC-Class II Expression and Rejection in a Puzzling Game," Nephrology Dialysis Transplantation, Vol. 15, No. 3, 2000, pp. 324332.

[3] I. Binet, V. Nickeleit, H. H. Hirsch, O. Prince, P. Dalquen, F. Gudat, M. J. Mihatsch and G. Thiel, "Polyomavirus
Disease under New Immunosuppressive Drugs: A Cause of Renal Graft Dysfunction and Graft Loss," Transplantation, Vol. 67, No. 6, 1999, pp. 918-922. doi:10.1097/00007890-199903270-00022

[4] V. Nickeleit, H. H. Hirsch, F. I. Binet, F. Gudat, O. Prince, P. Dalquen, G. Thiel and M. J. Mihatsch, "Polyomavirus Infection of Renal Allograft Recipients: From Latent Infection to Manifest Disease," Journal of the American Society of Nephrology, Vol. 10, No. 5, 1999, pp. 1080-1089.

[5] B. H. de Ligny, I. Etienne, A. Francois, O. Toupance, M. Buchler, G. Touchard, P. Lepogamp, F. Comoz, T. Lobbedez, M. Godin, J. P. Ryckelynck and Y. Lebranchu, "Polyomavirus-Induced Acute Tubulo-Interstitial Nephritis in Renal Allograft Recipients," Transplantation Proceedings, Vol. 32, No. 8, 2000, pp. 2760-2761. doi:10.1016/S0041-1345(00)01869-8

[6] M. Mayr, V. Nickeleit, H. H. Hirsch, M. Dickenmann, M. J. Mihatsch and J. Steiger, "Polyomavirus BK Nephropathy in a Kidney Transplant Recipient: Critical Issues of Diagnosis and Management," American Journal of Kidney Diseases, Vol. 38, No. 3, 2001, p. E13. doi:10.1053/ajkd.2001.26917

[7] V. Nickeleit, T. Klimkait, I. F. Binet, P. Dalquen, V. Del Zenero, G. Thiel, M. J. Mihatsch and H. H. Hirsch, "Testing for Polyomavirus Type BK DNA in Plasma to Identify Renal-Allograft Recipients with Viral Nephropathy," New England Journal of Medicie, Vol. 342, No. 18, 2000, pp. 1309-1315. doi:10.1056/NEJM200005043421802

[8] R. B. Colvin and S. Mauiyyedi, "Differential Diagnosis between Infection and Rejection in Renal Allografts," Transplantation Proceedings, Vol. 33, No. 1-2, 2001, pp. 1778-1779.

[9] C. J. Holman, J. A. van Burik, S. H. Hinrichs Jr. and H. H. Balfour Jr., "Specific Detection of Human BK Polyomavirus in Urine Samples of Immunocompromised Patients," Clinical and Diagnostic Laboratory Immunology, Vol. 10, No. 1, 2003, pp. 66-69.

[10] P. Randhawa, A. Ho, R. Shapiro, A. Vats, P. Swalsky, S. Finkelstein, J. Uhrmacher and K. Weck, "Correlates of Quantitative Measurement of BK Polyomavirus (BKV) DNA with Clinical Course of BKV Infection in Renal Transplant Patients," Journal of Clinical Microbiology, Vol. 42, No. 3, 2004, pp. 1176-1180. doi:10.1128/JCM.42.3.1176-1180.2004

[11] D. Cimbaluk, L. Pitelka, L. Kluskens and P. Gattuso, "Update on Human Polyomavirus BK Nephropathy," Diagnostic Cytopathology, Vol. 37, No. 10, 2009, pp. 773-779. doi: $10.1002 /$ dc. 21147

[12] H. H. Hirsch, D. C. Brennan, C. B. Drachenberg, F. Ginevri, J. Gordon, A. P. Limaye, M. J. Mihatsch, V. Nickeleit, E. Ramos, P. Randhawa, R. Shapiro, J. Steiger, M. Suthanthiran and J. Trofe, "Polyomavirus-Associated Nephropathy in Renal Transplantation: Interdisciplinary Analyses and Recommendations," Transplantation, Vol. 79, No. 10, 2005, pp. 1277-1286.

[13] M. S. Sachdeva, R. Nada, V. Jha, V. Sakhuja and K. Joshi, "The High Incidence of BK Polyoma Virus Infection among Renal Transplant Recipients in India," Transplan- 
taion, Vol. 77, No. 3, 2004, pp. 429-431. doi:10.1097/01.TP.0000113163.02039.30

[14] A. Egli, S. Köhli, M. Dickenmann and H. H. Hirsch, "Inhibition of Polyomavirus BK-Specific T-Cell Responses by Immunosuppressive Drugs," Transplantation, Vol. 88, No. 10, 2009, pp. 1161-1168. doi:10.1097/TP.0b013e3181bca422

[15] H. H. Hirsch and J. Steiger, "Polyomavirus BK," The Lancet Infectious Diseases, Vol. 3, No. 10, 2003, pp. 611623. doi:10.1016/S1473-3099(03)00770-9

[16] A. Y. Leung, M. Chan, S. C. Tang, R. Liang and Y. L. Kwong, "Real-Time Quantitative Analysis of Polyoma BK Viremia and Viruria in Renal Allograft Recipients," Journal of Virological Methods, Vol. 103, No. 1, 2002, pp. 51-56.

[17] C. Merlino, M. Bergallo, F. Giacchino, R. Daniele, C. Bollero, L. Comune, G. P. Segoloni and R. Cavallo, "Human Polyoma-Virus BK Monitoring by Quantitative PCR in Renal Transplant Recipients," Intervirology, Vol. 47, No. 1, 2004, pp. 41-47. doi:10.1159/000076641

[18] A. Dolei, V. Pietropaolo, E. Gomes, C. Di Taranto, M. Ziccheddu, M. A. Spanu, C. Lavorino, M. Manca and A. M. Degener, "Polyomavirus Persistance in Lymphocytes: Prevalence in Lymphocytes from Blood Donors and Healthy Personnel of a Blood Transfusion Centre," Journal of General Virology, Vol. 81, No. 8, 2000, pp. 19671973.

[19] C. B. Drachenberg, H. H. Hirsch, E. Ramos and J. C. Papadimitriou, "Polyomavirus Disease in Renal Trans- plantation, Review of Pathological Findings and Diagnostic Methods," Human Pathology, Vol. 36, No. 12, 2005, pp. 1245-1255. doi:10.1016/j.humpath.2005.08.009

[20] H. H. Hirsch, W. Knowles, M. Dickenmann, J. Passweg, T. Klimkait, M. J. Mihatsch and J. Steiger, "Prospective Study of Polyomavirus Type BK Replication and Nephropathy in Renal-Transplan Recipients," New England Journal of Medicine, Vol. 347, No. 7, 2002, pp. 488-496. doi:10.1056/NEJMoa020439

[21] Y. M. Barri, I. Ahmad, B. L. Ketel, G. W. Barone, P. D. Walker, S. M. Bonsib and S. R. Abul-Ezz, "Polyoma Viral Infection in Renal Transplantation: The Role of Immunosuppressive Therapy," Clinical Transplantation, Vol. 15, No. 4, 2001, pp. 240-246.

[22] E. Ramos, C. B. Drachenberg, J. C. Papadimitriou, O. Hamze, J. C. Fink, D. K. Klassen, R. C. Drachenberg, A. Wiland, R. Wali, C. B. Cangro, E. Schweitzer, S. T. Bartlett and M. R. Weir, "Clinical Course of Polyoma Virus Nephropathy in 67 Renal Transplant Patients," Journal of the American Society of Nephrology, Vol. 13, No. 8, 2002, pp. 2145-2151. doi:10.1097/01.ASN.0000023435.07320.81

[23] A. Sessa, A. Esposito, A. Giliberti, M. Bergallo, C. Costa, R. Rossano, E. Lettieri and M. Capuano, "BKV Reactivation in Renal Transplant Recipients: Diagnostic and Therapeutic Strategy-Case Reports," Transplantation Proceedings, Vol. 40, No. 6, 2008, pp. 2055-2058. doi:10.1016/j.transproceed.2008.05.007 